\title{
Dermoscopy in the Diagnosis of Cutaneous Leishmaniasis
}

\author{
Gamze Serarslan ${ }^{1}$, Özlem Ekiz², Cahit Özer³, Gökhan Sarıkaya ${ }^{4}$
}

\begin{abstract}
1 Mustafa Kemal University, Faculty of Medicine, Department of Dermatology, Hatay, Turkey
2 Medical Park Hospital, Department of Dermatology, Ordu, Turkey

3 Mustafa Kemal University, Faculty of Medicine, Department of Family Medicine, Hatay, Turkey

4 Magnet Hospital, Department of Dermatology, Kayseri, Turkey
\end{abstract}

Key words: dermoscopy, leishmaniasis, vascular, cutaneous

Citation: Serarslan G, Ekiz Ö, Özer C, Sarıkaya G. Dermoscopy in the diagnosis of cutaneous leishmaniasis. Dermatol Pract Concept. 2019;9(2):111-118. DOI: https://doi.org/10.5826/dpc.0902a06

Accepted: December 7, 2018; Published: April 30, 2019

Copyright: @2019 Serarslan et al. This is an open-access article distributed under the terms of the Creative Commons Attribution License, which permits unrestricted use, distribution, and reproduction in any medium, provided the original author and source are credited.

Funding: None.

Competing interests: The authors have no conflicts of interest to disclose.

Authorship: All authors have contributed significantly to this publication.

Corresponding author: Gamze Serarslan, MD, Mustafa Kemal University, Faculty of Medicine, Department of Dermatology, Hatay, Turkey. Email: gserarslan@hotmail.com

\footnotetext{
ABSTRACT Background: Cutaneous leishmaniasis (CL) is a protozoan infectious disease. Dermoscopy is a noninvasive diagnostic tool that has been applied to several skin diseases, including infestations.

Objectives: To determine the dermoscopic patterns of CL lesions and to investigate whether a relationship exists between dermoscopic characteristics and the disease duration, localization, and type of CL lesions.

Methods: Seventy-nine patients (48 male, 31 female) from Hatay, Turkey, were enrolled in the study and a dermoscopic evaluation was performed on 139 lesions. Images of CL lesions were taken via polarized light contact dermoscopy. Chi-square and Fisher exact tests were used for statistical analyses and $P$ values $<0.05$ were considered significant.

Results: Generalized erythema was seen in all CL lesions. Vascular structures $(94.2 \%)$, yellow tears $(75.5 \%)$, and a white starburst-like pattern $(58.3 \%)$ were the other most common dermoscopic features. Hyperkeratosis $(\mathrm{P}=0.001)$ and white starburst-like pattern $(\mathrm{P}<0.001)$ were more prevalent in the extremities than elsewhere. Among vascular structures, linear irregular (45.8\%), hairpin (43.5\%), and comma-shaped $(25.9 \%)$ patterns were the most common dermoscopic findings. Linear irregular $(\mathrm{P}=0.023)$ and arborizing vessels $(\mathrm{P}=0.001)$ were observed in the head-neck region. Dotted $(\mathrm{P}=$ 0.009), hairpin $(P<0.001)$, and glomerular-like $(P=0.016)$ morphological findings were more prevalent in the extremities. Statistical significances in disease duration were detected in microarborizing $(\mathrm{P}=0.027)$ and arborizing $(\mathrm{P}=0.004)$ vessels and were most prevalent with a disease duration of $>6$ months. Hairpin vessels were prevalent in the plaque and nodulo-ulcerative type of lesions. Dotted vessels were most commonly seen in the plaque type $(47.4 \%)$ of lesions.

Conclusions: Generalized erythema, yellow tears, and starburst-like patterns, as well as linear irregular, hairpin, comma-shaped, and arborizing vessels, were the most commonly detected dermoscopic features of CL lesions. We suggest that the presence of these features can be helpful when diagnosing CL lesions by dermoscopy.
} 


\section{Introduction}

Cutaneous leishmaniasis (CL) is a protozoan infectious disease caused by the Leishmania genus of flagellate protozoan, and the disease is widespread in most countries in the Mediterranean basin, including Turkey [1]. More than $70 \%$ of global CL cases occur in 10 countries (Afghanistan, Algeria, Brazil, Colombia, Costa Rica, Ethiopia, Islamic Republic of Iran, Peru, Sudan, and the Syrian Arab Republic) [2].

Dermoscopy is a noninvasive diagnostic tool that has been used in melanocytic lesions. Dermoscopy has also been also used in several skin diseases, such as inflammatory skin disorders, hair disorders, and infestations [3].

Although there have been a few studies about dermoscopic patterns of CL, there are conflicting results about the location, duration, type of lesions, and dermoscopic findings [4-6]. In this study, we aimed at determining the dermoscopic features of CL lesions and at investigating whether a relationship exists between the dermoscopic characteristics of CL lesions and the disease duration, localization, and type of lesion. In addition, the background color and distribution of vascular structures in the CL lesions were evaluated.

\section{Methods}

This prospective study was performed at a tertiary care hospital in the region Hatay, which is an endemic area for CL and located in the southern part of Turkey. The study was conducted in accordance with the Declaration of Helsinki. The local ethics committee approved the study (approval number 010620122-06), and informed consent was obtained from all participants. A total of 79 patients (48 male, 31 female; age range 2-85 years), who were seen in the dermatology outpatient clinic and were diagnosed with CL, were included in the study.

CL was diagnosed clinically, and the diagnosis was confirmed by a laboratory demonstration of the presence of the parasite in the smears obtained from the lesions. If the smear was negative, a histopathological examination was performed. Identification of Leishmania organisms in the histiocyte cytoplasm with Giemsa staining was also considered as Leishmania-positive. Exclusion criteria were any CL treatment (topical, intralesional, or systemic) before recruitment to the study.

Full demographic details and history of the disease, including age, gender, duration of the disease, localization, and clinical type of the lesion, were recorded in a predesigned clinical record form for each patient.

All CL lesions were evaluated following the diagnosis. The dermoscopic evaluation was performed by 2 clinicians (G.S., Ö.E.). Clinical and dermoscopic photographs of the lesions were performed with a polarized light contact dermoscopy
(Mole Max II, Derma Instruments, Vienna, Austria; 20- to 40 -fold magnification). We applied $70 \%$ alcohol or water over the lesions before taking dermoscopic images. When taking the images, we applied minimal downward pressure to visualize the vascular structures.

Dermoscopic evaluation of vascular structures was based on previous reports in the studies of Argenziano et al [7] and Zalaudek et al [8]. The background color of lesions was evaluated and performed according to the study presented by Lallas et al [3]. We also assessed the distribution of vascular structures in the CL lesions and categorized them into the following patterns: peripheral (observed predominantly at the periphery of the lesion), patchy (arranged in an asymmetrical distribution which could not be classified as clustered), central, regular (vessels distributed uniformly throughout the lesion), and cluster (aggregated in small groups) [3].

Data were analyzed using SPSS for Windows (version 13; SPSS Inc., Chicago, IL, USA). Values were given as mean \pm standard deviation (SD) or frequency and percent. Disease duration was dichotomized as $\leq 6$ months or $>6$ months. The dermoscopic characteristics of the CL lesions were compared with the duration of the disease, the location, and the type of lesion using the chi-square and Fisher exact tests. P values < 0.05 were considered significant.

\section{Results}

\section{Demographic Data}

One hundred thirty-nine CL lesions from 79 patients (48 male [60.76\%], 31 female [39.24\%]) were enrolled in the study. The mean age of the patients was $24.05 \pm 18.89$ (range, $2-85$ years; median, 17 years) and the duration of the disease was $8.68 \pm 20.63$ (range, $1-240$ months). The duration of the disease was $\leq 6$ months in $54.4 \%$ of patients and $>6$ months in $45.6 \%$ of patients. The most frequent lesion localization was the head, followed by the upper and lower extremities. CL lesions were described as papular, nodular, nodulo-ulcerative, and plaque type. Most of the lesions were nodules (42.4\%). The details of the clinical and demographic characteristics of the patients and lesions are shown in Table 1.

\section{Dermoscopic Findings}

\section{General Pattern}

The descriptive results of the dermoscopic analysis are shown in Table 2. The Fitzpatrick skin types of the patients were II and III. Generalized erythema was seen in all CL lesions. The color of erythema was dusky red (33.8\%), light red (43.9\%), and yellowish red $(22.3 \%)$ (Figure 1). Vascular structures $(94.2 \%)$, yellow tears $(75.5 \%)$, and white starburst-like pattern $(58.3 \%)$ were the other most common dermoscopic features (Figures 2 and 3). 
Table 1. Clinical and Demographic Characteristics of the Patients and Lesions Characteristics n (\%)

Sex

\begin{tabular}{|l|c|}
\hline Female & $48(60.7)$ \\
\hline Male & $31(39.2)$ \\
\hline Age (yrs), mean \pm SD & $24.05 \pm 18.89$ \\
\hline
\end{tabular}

Duration of disease, mean $\pm \mathrm{SD}$

\begin{tabular}{|l|r|}
\hline$\leq 6$ months & $43(54.4)$ \\
\hline$>6$ months & $36(45.6)$ \\
\hline Total no. of lesions & $139(100)$ \\
\hline
\end{tabular}

No. of lesions

\begin{tabular}{|c|c|}
\hline 1 & $52(65.8)$ \\
\hline 2 & $12(15.2)$ \\
\hline 3 & $4(5.1)$ \\
\hline 4 & $6(7.6)$ \\
\hline 5 & $3(3.8)$ \\
\hline 6 & $2(2.5)$ \\
\hline
\end{tabular}

Type of lesion

\begin{tabular}{|l|l|}
\hline Papular & $20(14.4)$ \\
\hline Nodular & $59(42.4)$ \\
\hline Nodulo-ulcerative & $33(23.7)$ \\
\hline Plaque & $27(19.4)$ \\
\hline
\end{tabular}

Location of lesions

Face

\begin{tabular}{|l|c|}
\hline Forehead & $7(5)$ \\
\hline Periorbital region & $3(2.2)$ \\
\hline Malar Region & $35(25.2)$ \\
\hline Ear & $1(0.7)$ \\
\hline Nose & $9(6.5)$ \\
\hline Lip & $5(3.6)$ \\
\hline Chin & $5(3.6)$ \\
\hline Neck & $3(2.2)$ \\
\hline
\end{tabular}

Upper extremities

\begin{tabular}{|l|c|}
\hline Shoulder & $3(2.2)$ \\
\hline Arm & $31(22.3)$ \\
\hline Elbow & $7(5.0)$ \\
\hline Hand & $19(13.7)$ \\
\hline
\end{tabular}

\begin{tabular}{|l|l|}
\hline Lower extremities & \\
\hline Leg & $5(3.6)$ \\
\hline Knee & $1(0.7)$ \\
\hline Foot & $5(3.6)$ \\
\hline
\end{tabular}

Hyperkeratosis and white starburst-like pattern were more prevalent in the extremities than elsewhere $(\mathrm{P}=0.001$ and $\mathrm{P}<0.001$, respectively). However, there was no statistically significant difference in color of erythema, hyperkeratosis + erosion/ulceration $(\mathrm{HK}+\mathrm{E} / \mathrm{U})$, yellow tears, and milia
Table 2. Dermoscopic Features in CL Dermoscopic Features

n (\%)

General features

\begin{tabular}{|c|c|}
\hline Erythema & $139(100)$ \\
\hline Dusky red & $47(33.8)$ \\
\hline Light red & $61(43.9)$ \\
\hline Yellowish red & $31(22.3)$ \\
\hline Hyperkeratosis & $49(35.3)$ \\
\hline $\mathrm{CE} / \mathrm{U}$ & $10(7.2)$ \\
\hline $\mathrm{HK}+\mathrm{E} / \mathrm{U}$ & $23(16.5)$ \\
\hline Yellow tears & $105(75.5)$ \\
\hline White starburst-like pattern & $81(58.3)$ \\
\hline White scar-like patch & $7(5.0)$ \\
\hline Milia-like cyst & $12(8.6)$ \\
\hline Yellowish hue & $1(0.7)$ \\
\hline Salmon-colored ovoid & $4(2.9)$ \\
\hline Vascular features & $131(94.2)$ \\
\hline Comma-shaped & $34(25.9)$ \\
\hline Linear irregular & $60(45.8)$ \\
\hline Dotted & $19(14.5)$ \\
\hline Hairpin & $57(43.5)$ \\
\hline Arborizing & $24(18.3)$ \\
\hline Corkscrew & $5(3.8)$ \\
\hline Glomerular-like & $28(21.4)$ \\
\hline Milky red globules/areas & $15(11.4)$ \\
\hline Microarborizing & $21(16.0)$ \\
\hline Crown & $4(3.0)$ \\
\hline
\end{tabular}

with regard to localization of CL ( $\mathrm{P} \geq 0.05)$. Dermoscopic structures including central erosion/ulceration (CE/U), white scar-like patch, yellowish hue, and salmon-colored ovoid, corkscrew, and crown were not included in the statistical analysis because of low rate of these features.

Hyperkeratosis was more prevalent in CL lesions with a disease duration of $\leq 6$ months $(P=0.036)$. There were no statistically significant differences between the disease duration and color of erythema, $\mathrm{HK}+\mathrm{E} / \mathrm{U}$, yellow tears, white starburst-like pattern, and milia $(\mathrm{P} \geq 0.05)$. There was also no statistically significant difference between the disease duration and CL type $(\mathrm{P}=0.605)$. The features, including $\mathrm{CE} / \mathrm{U}$, yellowish hue, salmon-colored ovoid, and white scar-like patch, were not included in the statistical analysis because of low rate of these features.

\section{Vascular Morphology}

Linear irregular $(45.8 \%)$, hairpin $(43.5 \%)$, and commashaped $(25.9 \%)$ patterns were the most common dermoscopic findings among vascular structures. Vascular structures, including linear irregular, dotted, hairpin, arborizing, 


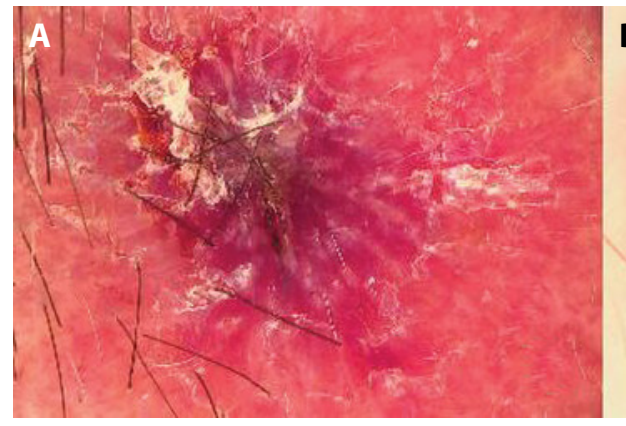

\section{B}

Figure 1. Examples of background color with polarized light contact dermoscopy (PlCD). (A) Dusky red (PlCD $\times 20)$. (B) Light red $(\mathrm{PlCD}$ $\times$ 40). (C) Yellowish red $(\mathrm{PlCD} \times 30)$. [Copyright: (O2019 Serarslan et al.]

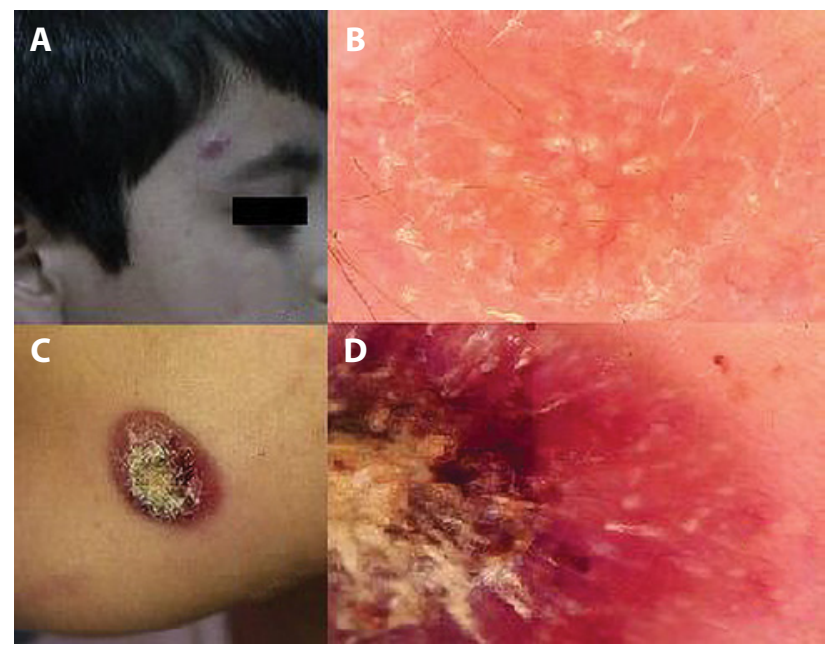

Figure 2. (A,C) Clinical picture of CL lesion. (B) Dermoscopically lesion reveals yellow tears $(\mathrm{PICD} \times 30)$. (D) Yellow tears with central crust $(\mathrm{PICD} \times 30)$. [Copyright: $\odot 2019$ Serarslan et al.]

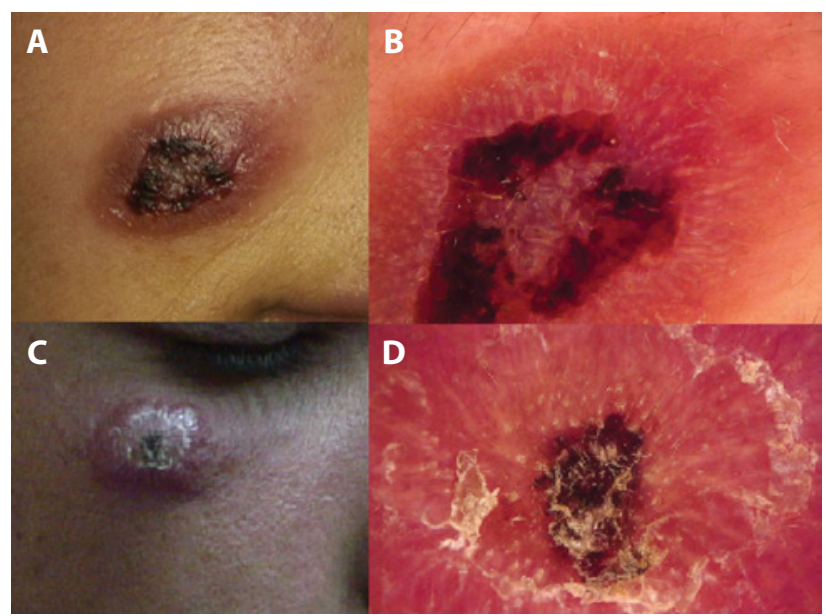

Figure 3. $(A, C)$ Clinical features of leishmaniasis. (B,D) Examples of starburst-like pattern $(\mathrm{PlCD} \times 20$ and $\times 30)$. [Copyright: $\odot 2019$ Serarslan et al.]

Table 3. Distribution of Vascular Structures

\begin{tabular}{|l|c|c|c|c|c|c|} 
& $\begin{array}{c}\text { Peripheral } \\
\mathbf{n}(\mathbf{\%})\end{array}$ & $\begin{array}{c}\text { Patchy } \\
\mathbf{n ( \% )}\end{array}$ & $\begin{array}{c}\text { Central } \\
\mathbf{n ~ ( \% )}\end{array}$ & $\begin{array}{c}\text { Regular } \\
\mathbf{n}(\mathbf{\%})\end{array}$ & $\begin{array}{c}\text { Cluster } \\
\mathbf{n}(\mathbf{\%})\end{array}$ & $\begin{array}{c}\text { Total } \\
\text { (n) }\end{array}$ \\
\hline Comma-shaped & $10(29.4)$ & $15(44.1)$ & $4(11.8)$ & $1(2.9)$ & $4(11.8)$ & 34 \\
\hline Linear irregular & $29(48.3)$ & $14(23.3)$ & $4(6.7)$ & $10(16.7)$ & $3(5.0)$ & 60 \\
\hline Dotted & $10(52.6)$ & $4(21.0)$ & - & $2(10.5)$ & $3(15.8)$ & 19 \\
\hline Hairpin & $24(42.1)$ & $17(29.8)$ & - & $7(12.3)$ & $9(15.8)$ & 57 \\
\hline Arborizing & $20(83.3)$ & - & - & $4(16.7)$ & - & 24 \\
\hline Corkscrew & $3(60.0)$ & $1(20.0)$ & $1(20.0)$ & - & - & 5 \\
\hline Glomerular & $15(53.6)$ & $9(32.1)$ & - & $2(7.1)$ & $2(7.1)$ & 28 \\
\hline Crown & $3(75.0)$ & $1(25.0)$ & - & - & - & 4 \\
\hline Microarborizing & $7(33.3)$ & $2(9.5)$ & - & $12(57.7)$ & - & 21 \\
\hline Milky red areas & $5(33.3)$ & $5(33.3)$ & $4(26.7)$ & - & $1(6.7)$ & 15 \\
\hline
\end{tabular}

glomerular-like, crown, and corkscrew types, were most commonly seen in the peripheral distribution. The distributions of vascular structures are shown in Table 3. In 54.7\% of lesions, there were 2 or more vascular structures, and most of the lesions were the nodular type (39.5\%). Hairpinlike vessels were most frequently combined with linear and glomerular-like vessels.
Linear irregular and arborizing vessels were observed in the head-neck localization in $60.0 \%$ and $79.2 \%$ of lesions, respectively, with a statistically significant difference ( $\mathrm{P}=$ 0.023 and $\mathrm{P}=0.001$, respectively). Dotted $(78.9 \%)$, hairpin $(70.2 \%)$, and glomerular-like (71.4\%) morphology were more prevalent in the extremity localizations $(\mathrm{P}=0.009, \mathrm{P}<$ 0.001 , and $\mathrm{P}=0.016$, respectively). There was no statistically 
Table 4. Dermoscopic Features According to the Types of CL Lesions

\begin{tabular}{|c|c|c|c|c|c|}
\hline & $\begin{array}{c}\text { Papule } \\
\text { (n) }\end{array}$ & $\begin{array}{c}\text { Plaque } \\
\text { (n) }\end{array}$ & $\begin{array}{c}\text { Nodule } \\
\text { (n) }\end{array}$ & $\begin{array}{l}\text { NU } \\
\text { (n) }\end{array}$ & $\begin{array}{c}\text { Total } \\
\text { (n) }\end{array}$ \\
\hline \multicolumn{6}{|l|}{ General features } \\
\hline Erythema & 20 & 27 & 59 & 33 & 139 \\
\hline Hyperkeratosis & 3 & 19 & 23 & 4 & 49 \\
\hline $\mathrm{CE} / \mathrm{U}$ & 1 & - & 2 & 7 & 10 \\
\hline $\mathrm{HK}+\mathrm{E} / \mathrm{U}$ & - & 1 & 2 & 20 & 23 \\
\hline Yellow tears & 13 & 23 & 44 & 25 & 105 \\
\hline White starburst-like & 2 & 23 & 27 & 29 & 81 \\
\hline White scar-like & - & 2 & 4 & 1 & 7 \\
\hline Milia-like cyst & 1 & 4 & 3 & 4 & 12 \\
\hline Yellowish hue & - & - & 1 & - & 1 \\
\hline Salmon-colored ovoid & - & 1 & 3 & - & 4 \\
\hline \multicolumn{6}{|l|}{ Vascular features } \\
\hline Comma-shaped & 4 & 7 & 16 & 7 & 34 \\
\hline Linear irregular & 7 & 12 & 30 & 11 & 60 \\
\hline Dotted & - & 9 & 3 & 7 & 19 \\
\hline Hairpin & 2 & 19 & 17 & 19 & 57 \\
\hline Arborizing & 2 & 2 & 15 & 5 & 24 \\
\hline Corkscrew & - & 2 & 1 & 2 & 5 \\
\hline Glomerular-like & 5 & 7 & 9 & 7 & 28 \\
\hline Milky red globules/areas & 1 & 2 & 4 & 8 & 15 \\
\hline Microarborizing & 4 & 2 & 12 & 3 & 21 \\
\hline Crown & - & 2 & 2 & - & 4 \\
\hline
\end{tabular}

$\mathrm{NU}=$ nodulo-ulcerative

significant difference in comma-shaped, microarborizing, and milky red areas with regard to the localization of CL lesions $(\mathrm{P} \geq 0.05)$.

A statistically significant difference was detected only in microarborizing vessels with regard to the disease duration among vascular structures, which was more prevalent with the disease duration $>6$ months $(\mathrm{P}=0.027)$.

Hairpin vessels were more prevalent in the plaque $(\mathrm{n}=$ $19)$ and nodulo-ulcerative $(\mathrm{n}=19)$ type of lesions. More than half $(53.3 \%)$ of the milky red areas were seen in the nodulo-ulcerative type of lesions. The majority of the nodular type of CL lesions presented comma-shaped, linear irregular, arborizing, microarborizing, and glomerular type of vessels. Dotted vessels were most commonly seen in the plaque type $(47.4 \%)$ of lesions. Dermoscopic features according to the types of CL lesions are shown in Table 4. Examples of the vascular structures are shown in Figure 4.

\section{Discussion}

We detected that generalized erythema (100\%), vascular structures $(94.2 \%)$, yellow tears $(75.5 \%)$, and white star- burst-like pattern $(58.3 \%)$ were the most common dermoscopic features in CL lesions. Similar to our study, Llambrich et al [9], Ayhan et al [4], and Yücel et al [5] also reported that generalized erythema was present in all lesions. However, in their study, Taheri et al [6] reported that generalized erythema was present in $81.9 \%$ of lesions and was more common in advanced and ulcerated lesions. We also detailed the color of erythema as dusky red (33.8\%), light red (43.9\%), and yellowish red $(22.3 \%)$. We detected no significant differences in our analyses of the color of erythema and disease duration and localization. However, we detected that $45.5 \%$ of dusky red lesions were of the nodulo-ulcerative type, $63 \%$ of light red lesions were the plaque type, and $50 \%$ of yellowish red lesions were the papular type.

Yellow tear-like structures were the third most common dermoscopic finding in our study. These structures were observed both in the head-neck region $(52.4 \%)$ and extremities $(47.6 \%)$. Although in several studies these structures have been reported only on the face and neck $[4,5]$, in another study [6] extremities were reported to be the more prevalent localization. Similar to other studies, in our study yellow tearlike structures were more common in lesions with a duration 


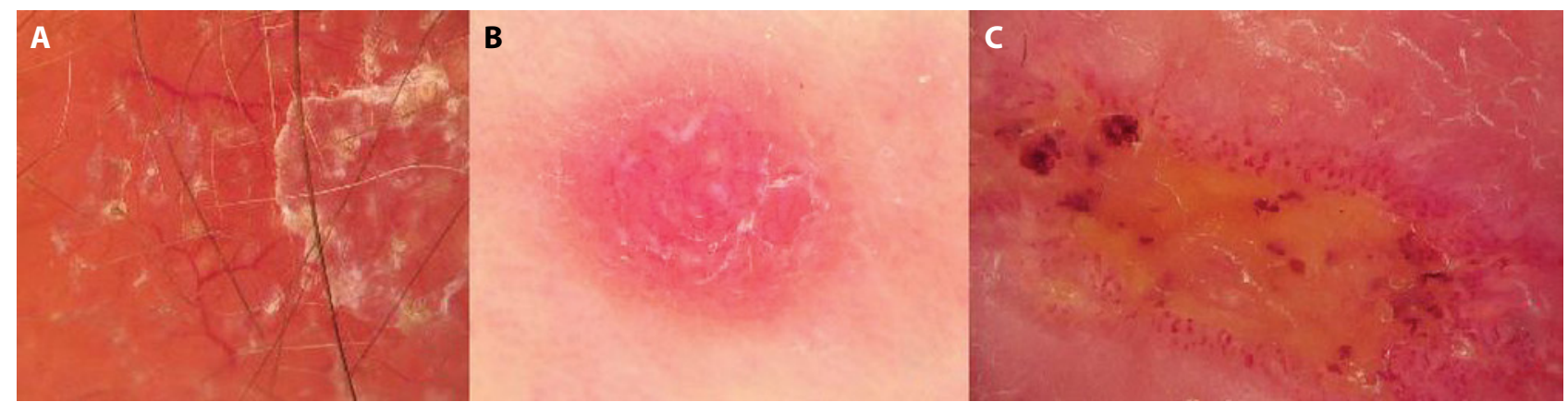

Figure 4. Vascular structures of CL lesions $(\mathrm{PICD} \times 40)$. (A) Arborizing vessels with peripheral distribution. (B) Regularly distributed hairpin vessels. (C) Microarborizing vessels. [Copyright: (02019 Serarslan et al.]

of $\leq 6$ months $(58.1 \%)[5,9]$. These structures were seen mostly in the nodular type $(41.9 \%)$ of lesions followed by the nodulo-ulcerative $(23.8 \%)$, plaque $(21.9 \%)$, and papule $(12.4 \%)$ type. Taheri et al [6] reported that these structures were more prevalent in ulcerated plaques. Yücel et al [5] reported that yellow tear-like structures were observed more commonly in nodules.

We detected that the white starburst-like pattern was more prevalent in the extremities localization and noduloulcerative type of lesions. In $61.7 \%$ of lesions, the disease duration was $\leq 6$ months. Yücel et al [5] reported that the white starburst-like pattern was observed more commonly in nodulo-ulcerative lesions and lesions with durations of 0-6 and 7-12 months. Also, Llambrich et al [9] detected that the white starburst-like pattern was more prevalent in the extremities. However, in another study, in contrast to our findings, these authors reported that this pattern was more prevalent in lesions older than 6 months and was related to nodular lesions [6].

Vascular structures, including linear irregular $(45.8 \%)$, hairpin $(43.5 \%)$, and comma-shaped (25.9\%) morphology, were the most common dermoscopic findings among vascular structures in our study. Although previous studies reported conflicting results on these common vascular structures, most of them, including in our study, showed that linear irregular and hairpin vessels were the most common (Table 5). We also evaluated the distribution of vascular structures in the lesions. As shown in Table 3, most of the vascular structures were present in peripheral distribution.

The linear irregular type of vascular morphology was more prevalent in the head-neck region. The linear irregular vascular morphology was seen mostly in the nodular $(50.0 \%)$ and plaque $(20.0 \%)$ type of lesions. The distribution of linear irregular vascular structure in the CL lesions represented peripheral $(48.3 \%)$, followed by patchy $(23.3 \%)$ and regu$\operatorname{lar}(16.7 \%)$. Duration of the disease was $\leq 6$ months in 34 $(56.7 \%)$ lesions and $>6$ months in $26(43.3 \%)$ lesions, and there was no statistical significance. Similar to our study, the face has been reported to be the most common localization of linear irregular vessels [4]. However, in another study, linear irregular vessels were reported to be more common in advanced lesions and not related to the lesion site [6].

Comma-shaped vessels were seen mostly in the nodular type $(47.1 \%)$ of lesions and were not related to the lesion site (head-neck, $52.9 \%$; extremity, $47.1 \%$ ) or duration of the disease. In our study, the distribution of comma-shaped vessels was mostly in the patchy pattern $(44.1 \%)$. The prevalence of hairpin vessels has been reported to be between $17 \%$ and $43.5 \%$ in CL lesions. We found that hairpin vessels were more prevalent in the extremities and that these structures were more common in advanced lesions, but were not related to the lesion site. Hairpin vessels were seen mostly in the plaque and nodulo-ulcerative type of lesions. Other studies, including Ayhan et al [4], Llambrich et al [9], and Yücel et al [5], also reported that extremities were the most common site and were observed in nodulo-ulcerative lesions. In contrast, Taheri et al [6] reported that hairpin vessels were not related to the type of skin lesions.

We differentiated arborizing structures as arborizing or microarborizing based on the study of Zalaudek et al. Microarborizing vessels represented a variation of arborizing vessels and were defined as linear straight/linear serpentine vessels with a small caliber [8]. The arborizing type of vascular morphology was most prevalent in the head-neck region. However, no statistical difference was detected for microarborizing vessels when comparing lesion sites. Both structures were more frequent in the nodular type of lesions, and also both of these structures were common when the disease duration was $>6$ months.

\section{Conclusions}

CL presents a variety of dermoscopic patterns that might cause difficulties during dermoscopic diagnosis. When we compared the most frequent first 5 findings for general dermoscopic and vascular features, we found that generalized erythema, yellow tears, and white starburst-like patterns, as well as and linear irregular, hairpin, comma-shaped, and 
Table 5. Dermoscopic Features of CL in the 5 Performed Studies

\begin{tabular}{|c|c|c|c|c|c|}
\hline Dermoscopic Features & $\begin{array}{l}\text { Llambrich et al [9] } \\
\qquad(n=26) \\
\%\end{array}$ & $\begin{array}{c}\text { Taheri et al [6] } \\
\begin{array}{c}(n=144) \\
\%\end{array}\end{array}$ & $\begin{array}{c}\text { Yücel et al [5] } \\
(n=145) \\
\%\end{array}$ & $\begin{array}{c}\text { Ayhan et al [4] } \\
\qquad(n=127) \\
\%\end{array}$ & $\begin{array}{c}\text { Current Study } \\
\qquad(n=139) \\
\%\end{array}$ \\
\hline \multicolumn{6}{|l|}{ General features } \\
\hline Generalized erythema & 100 & 81.9 & 100 & 100 & 100 \\
\hline Yellow tears & 53 & 41.7 & 40 & 42.5 & 75.5 \\
\hline $\begin{array}{l}\text { White starburst-like } \\
\text { pattern }\end{array}$ & 38 & 60.4 & 19 & 8.6 & 58.3 \\
\hline Hyperkeratosis & 50 & 33.3 & - & 15 & 35.3 \\
\hline $\mathrm{HK}+\mathrm{E} / \mathrm{U}$ & 38 & - & 35 & - & 16.5 \\
\hline Milia-like cyst & - & 4.9 & - & 15.7 & 8.6 \\
\hline Salmon-colored ovoid & - & - & 13 & 15.7 & 2.9 \\
\hline $\mathrm{CE} / \mathrm{U}$ & 46 & 59 & - & 44.1 & 7.2 \\
\hline Yellowish hue & - & 43.8 & - & - & 0.7 \\
\hline $\begin{array}{l}\text { Perilesional } \\
\text { hypopigmented halo }\end{array}$ & - & - & 3 & - & - \\
\hline $\begin{array}{l}\text { Scar (white scar-like } \\
\text { patch) }\end{array}$ & - & - & - & 17.3 & 5.0 \\
\hline Pustules & - & - & - & 7.1 & - \\
\hline Crust & - & - & - & 70.1 & - \\
\hline Vascular features & 100 & & 87 & 90.6 & 94.2 \\
\hline Glomerular-like vessels & 7 & 22.9 & 17 & 3.1 & 21.4 \\
\hline Hairpin vessels & 19 & 37.5 & 17 & 39.4 & 43.5 \\
\hline Linear irregular vessels & 57 & 30.6 & 54 & 26 & 45.8 \\
\hline Arborizing telangiectasia & 11 & 10.4 & 37 & 38.6 & 18.3 \\
\hline Crown-like vessels & - & - & - & 1.6 & 3.0 \\
\hline Dotted vessels & 53 & 61.1 & 16 & 24.4 & 14.5 \\
\hline Comma-shaped vessels & 73 & 29.9 & 4 & 19.7 & 25.9 \\
\hline $\begin{array}{l}\text { Polymorphous/atypical } \\
\text { vessels }\end{array}$ & 26 & - & 3 & 40.2 & 15.2 \\
\hline Corkscrew vessels & 7 & 4.2 & - & 3.1 & 3.8 \\
\hline Strawberry pattern & - & - & - & 1.6 & - \\
\hline Milky red globules/areas & - & - & - & - & 11.4 \\
\hline Microarborizing & - & - & - & - & 16.0 \\
\hline
\end{tabular}

-Not reported or evaluated.

arborizing vessels, were associated with CL lesions in our study, as well as in most previous studies. Therefore, we suggest that the presence of these parameters will help during the diagnosis of CL lesions by dermoscopy. We also think that dermoscopy can be used more reliably in the diagnosis of CL by comparing the dermoscopic features of the diseases with similar clinical appearances, such as other granulomatous diseases [10] and cutaneous B-cell lymphoma [11-13].

\section{References}

1. Uz OK, Balcıŏlu IC, Taylan Özkan A, Ozensoy S, Ozbel Y. Leishmaniasis in Turkey. Acta Trop. 2002;84(1):43-48.
2. WHO. Leishmaniasis in high-burden countries: an epidemiological update based on data reported in 2014. Wkly Epidemiol Rec. 2016;91(22):287-296.

3. Lallas A, Kyrgidis A, Tzellos TG, et al. Accuracy of dermoscopic criteria for the diagnosis of psoriasis, dermatitis, lichen planus and pityriasis rosea. Br J Dermatol. 2012;166(6):1198-1205.

4. Ayhan E, Ucmak D, Baykara SN, Akkurt ZM, Arica M. Clinical and dermoscopic evaluation of cutaneous leishmaniasis. Int J Dermatol. 2015;54(2):193-201.

5. Yücel A, Günasti S, Denli Y, Uzun S. Cutaneous leishmaniasis: new dermoscopic findings. Int J Dermatol. 2013;52(7):831-837.

6. Taheri AR, Pishgooei N, Maleki M, et al. Dermoscopic features of cutaneous leishmaniasis. Int J Dermatol. 2013;52(11):1361-1366. 
7. Argenziano G, Zalaudek I, Corona R, et al. Vascular structures in skin tumors. Arch Dermatol. 2004;140(12):1485-1489.

8. Zalaudek I, Kreusch J, Giacomel J, Ferrara G, Catriacala C, Argenziano G. How to diagnose nonpigmented skin tumors: a review of vascular structures seen with dermoscopy, part I: melanocytic skin tumors. J Am Acad Dermatol. 2010;63(3):361-374.

9. Llambrich A, Zaballos P, Terrasa F, Torne I, Puig S, Malvehy L. Dermoscopy of cutaneous leishmaniasis. Br J Dermatol. 2009;160(4):756-761.

10. Errichetti E, Stinco G. Dermoscopy of granulomatous disorders. Dermatol Clin. 2018;36(4):369-375.
11. Piccolo V, Russo T, Agozzino M, et al. Dermoscopy of cutaneous lymphoproliferative disorders: where are we now? Dermatology. 2018;234(3-4):131-136.

12. Piccolo V, Mascolo M, Russo T, Staibano S, Argenziano G. Dermoscopy of primary cutaneous B-cell lymphoma (PCBCL). J Am Acad Dermatol. 2016;75(4):e137-e139.

13. Mascolo M, Piccolo V, Argenziano G, et al. Dermoscopy pattern, histopathology and immunophenotype of primary cutaneous Bcell lymphoma presenting as a solitary skin nodule. Dermatology. 2016;232(2):203-207. 